\title{
Tdap vaccination in pregnancy
}

\author{
Daniel Dalcin MD, Scott A. Halperin MD
}

Cite as: CMAJ 2021 June 14;193:E911. doi: 10.1503/cmaj.202420

1

\section{Most severe pertussis infections occur in infants}

A Canadian study of children ( $<17 \mathrm{yr}$ ) who were hospitalized for pertusis from 1999-2015 found that infants younger than 2 months had the highest incidence of admission to hospital (116.40, 95\% confidence interval [CI] 85.32-147.49 per 100000 population) and to the intensive care unit $(33.48,95 \% \mathrm{Cl} 26.35-$ 40.62 per 100000 population). All fatal cases of pertussis involved infants aged 3 months and younger. ${ }^{1}$

2 Vaccination against tetanus toxoid, reduced diphtheria toxoid, and acellular pertussis (Tdap) in pregnancy has been recommended in Canada since 2018

In 2018, the Canadian National Advisory Committee on Immunization changed their guidance to recommend Tdap vaccination at 27-32 weeks' gestation in each pregnancy, irrespective of previous immunizations, based on multiple international maternal immunization studies that showed vaccine efficacy. ${ }^{2}$

\section{3}

Infants receive passive immune protection from

maternal Tdap vaccinations during pregnancy

Infants born to mothers immunized with Tdap during pregnancy benefit from transplacental transfer of maternal pertussis antibodies, allowing for immunity in the first months of life, when infants are most at risk of severe pertussis and death. ${ }^{3} \mathrm{~A}$ retrospective cohort study involving 148981 infants found maternal Tdap vaccination was associated with a $91.4 \%(95 \% \mathrm{Cl}$ 19.5-99.1) reduction in the risk of pertussis among infants in the first 2 months and $69.0 \%(95 \% \mathrm{Cl} 43.6 \%-82.9 \%)$ in the first 12 months of life. ${ }^{4}$

\section{Tdap vaccination in pregnancy is safe}

In 2011, the American College of Obstetricians and Gynecologists began recommending Tdap vaccination during pregnancy. Numerous surveillance studies now support its safety and efficacy. ${ }^{5} \mathrm{~A}$ recent randomized, controlled, observer-blind, multicentre clinical trial showed no difference in rates of maternal-fetal adverse events between patients who received the Tdap vaccine and those who received the tetanusdiphtheria vaccine. ${ }^{6}$

\section{5}

\section{Cocooning is no longer recommended}

Vaccinating family members and close contacts to provide a "cocoon" of protection for the infant is no longer recommended; however, vaccination of individuals who have not previously received the Tdap vaccine is still encouraged. ${ }^{2,5}$

\section{References}

1. Abu-Raya B, Bettinger JA, Vaderkooi OG, et al.; Members of the Canadian Immunization Monitoring Program, Active (IMPACT). Burden of children hospitalized with pertussis in Canada in the acellular pertussis vaccine era, 1999-2015. J Pediatric Infect Dis Soc 2020;9:118-27.

2. Update on immunization in pregnancy with Tdap vaccine: Update on immunization in pregnancy with tetanus toxoid, reduced diphtheria toxoid and reduced acellular pertussis (Tdap) vaccine. Public Health Agency of Canada; 2018, modified 2019 Oct. 9. Available: www.canada.ca/en/ public-health/services/publications/healthy-living/update-immunization -pregnancy-tdap-vaccine.html (accessed 2021 Mar. 5).

3. Abu Raya B, Edwards KM, Scheifele DW, et al. Pertussis and influenza immunisation during pregnancy: a landscape review. Lancet Infect Dis 2017;17:e209-22.

4. Baxter R, Bartlett, Fireman B, et al. Effectiveness of vaccination during pregnancy to prevent infant pertussis. Pediatrics 2017;139. doi: 10.1542/ peds.2016-4091.

5. Update on immunization and pregnancy: tetanus, diphtheria, and pertussis vaccination. ACOG Committee Opinion 718. Washington (DC): American College of Obstetricians and Gynecologists (ACOG). 2017. Available: www.acog.org/clinical/clinical-guidance/committee-opinion/ articles/2017/09/update-on-immunization-and-pregnancy-tetanus -diphtheria-and-pertussis-vaccination (accessed 2021 Mar. 5).

6. Halperin SA, Langley JM, Ye L. A randomized controlled trial of the safety and immunogenicity of tetanus, diphtheria, and acellular pertussis vaccine immunization during pregnancy and subsequent infant immune response. Clin Infect Dis 2018;67:1063-71.

Competing interests: Scott Halperin reports grants from GSK and Sanofi Pasteur related to research on pertussis-containing vaccines, as well as occasionally serving on advisory boards. He also reports payment for expert testimony by the province of Ontario regarding vaccine-associated adverse events. Scott Halperin is a member of a consortium that holds a patent for a novel adjuvant related to pertussis vaccines. He has also served on a clinical trial's Data Safety Monitoring Board for pertussis vaccines in pregnancy. No other competing interests were declared.

This article has been peer reviewed.

Affiliations: Faculty of Medicine (Dalcin), Dalhousie University; Departments of Pediatrics, and of Microbiology \& Immunology (Halperin); Canadian Centre for Vaccinology, Dalhousie University; IKW Health and Nova Scotia Health, Halifax, NS

Content licence: This is an Open Access article distributed in accordance with the terms of the Creative Commons Attribution (CC BY-NC-ND 4.0) licence, which permits use, distribution and reproduction in any medium, provided that the original publication is properly cited, the use is noncommercial (i.e., research or educational use), and no modifications or adaptations are made. See: https://creativecommons.org/licenses/by-nc-nd/4.0/

Correspondence to: Daniel Dalcin, ddalcin@nosm.ca 